\title{
Reflexiones en torno al estudio de los retablos portátiles peruanos y las cajas de imaginero del siglo XIX
}

\author{
Magaly Patricia Labán Salguero \\ Contacto: magaly.labans@gmail.com
}

\section{Resumen}

$\mathrm{El}$ artículo es una aproximación al estudio de los retablos portátiles peruanos y las cajas de imagineros del siglo XIX. La investigación plantea una revisión de las diversas denominaciones americanas de los "retablos", la pertinencia de términos como: retablo religioso, retablo portátil, capilla-retablo, demanda, caja de imaginero, nicho, tríptico, cajón sanmarkos y missa. Breve análisis de los antecedentes históricos y formales de las cajas de imaginero del siglo XIX. Se presenta el estado de la cuestión y se reflexiona sobre los conceptos e influencias teóricas de los investigadores, analizando sus aportes metodológicos y conceptuales. Considerando la falta de datación de las obras y la filiación de talleres, así como las dificultades metodológicas y los métodos empleados por los investigadores.

Palabras clave: retablos, cajas de imaginero, retablo portátil peruano.

\section{Abstract}

This article is an approximation to the study of peruvian portable altarpieces and "cajas de imagineros" of XIX century. This research propose a revision of diverse american denominations of altarpieces, pertinence of names such as: religious altarpiece, portable altarpiece, "capilla- retablo", "demanda", "caja de imaginero", niche, triptych, "cajón sanmarkos" and "missa". Analysing briefly historical backgrounds and standards of "cajas de imaginero" of XIX century. Presenting an state of the question and reflecting about concepts and theoretical influences of researchers, analysing their methodological and conceptual contributions. Considering the lack of chronological dating in those work of art pieces and workshop filiations, researcher's methodological difficulties and their applied methods.

Key words: retablos, cajas de imaginero, retablo portátil peruano. 


\section{Reflexiones en torno al estudio de los retablos portátiles peruanos y las cajas de imaginero del siglo XIX}

\section{Introducción}

La historia de los retablos portátiles peruanos y las cajas de imaginero es una tarea pendiente. Los principales estudios nacionales y extranjeros provienen de las ciencias sociales, especialmente de la antropología; las pocas investigaciones de la historia del arte analizan los retablos virreinales, el cajón sanmarkos y el retablo ayacuchano usando el método sociológico e iconográfico, pero nos parece pertinente el uso del método formalista y el análisis histórico-crítico para valorar la obra en su aspecto formal y plástico; reconstruir la época y la ideología que les dio la forma, así como la mentalidad y la cultura detrás de la materialidad que ostentan estas cajitas de devoción. Por consiguiente, el análisis formalista es de vital importancia para comprender la obra de arte, la configuración y las técnicas empleadas en los retablos y cajas de imaginero del siglo XIX.

Las cajas de imaginero utilizan un repertorio formal arcaizante con elementos de épocas anteriores y técnicas que van cayendo en el olvido, pero las formas viven plenamente y se trasforman; manteniéndose modos de hacer y formas en la periferia. Además, se considera el método histórico-crítico por ser integrador de diversas disciplinas del saber, ya que promueve una mirada abierta y basada en el rigor histórico, así como en el uso de las fuentes.

Los retablos portátiles americanos evidencian estilos anacrónicos y manufactura variada; son usuales en el área del Virreinato del Perú, ahora territorio peruano, boliviano, chileno y argentino. Los más antiguos posiblemente fueron realizados en Cusco y en el Alto-Perú (Bolivia), luego se difundieron por la ruta del Camino Real, las rutas de la plata y los caminos de los arrieros. En Bolivia existieron varios centros de producción como Potosí y Cochabamba, así como diversos talleres cerca al santuario de la Virgen de Copacabana. Las rutas de la plata fueron importantes en la difusión de los retablos portátiles debido a que surgieron santuarios y devociones andinas, destacando el santuario de la Virgen 
de Copacabana, centro religioso y de peregrinación de los Andes, ubicado cerca al camino Lima-Potosí. Es posible, que en las inmediaciones del santuario se comenzara a manufacturar un pequeño retablo de caja de plata que reproducía el altar mayor de la Virgen de Copacabana, siendo un relieve de estuco policromado (Kusunoki \& Wuffarden, 2018, p. 32).

En este artículo se considerará dos tipos de cajas de imaginero del siglo XIX: las cajas de imaginero de Chucuito y la caja de imaginero sanmarkos-sanlucas, también conocida como cajón sanmarkos o sanmarcos.

El cajón sanmarkos es una caja de imaginero que presenta dos pisos: en el superior se ubican las figuras de los santos patronos de los animales domésticos, usualmente los santos son representados siguiendo la ley de la frontalidad, y se muestran hieráticos; así tenemos a San Marcos, San Lucas, San Juan Bautista, Santa Inés y San Antonio; ellos miran al espectador desde la atemporalidad de lo divino, cual iconos bizantinos. Mientras en el piso inferior se representa las escenas del mundo campesino, que son de vital importancia dentro de una economía agrícola y pastoril. La mayoría de cajones sanmarkos son datados a fines del siglo XIX o comienzos del XX.

Por otro lado, sobre las cajas de imaginero chucuiteñas o trípticos de Chucuito, solo existen breves referencias, aunque es indudable la amplia difusión de esta tipología de cajas o retablos portátiles de la Virgen de la Candelaria o de Copacabana. La caja de imaginero es de reducidas dimensiones, formalmente es un tríptico religioso católico europeo. Mendizábal considera que son disímiles en manufactura y tamaño, por ese motivo las clasifica en dos tipos: "A", y "B", teniendo en cuenta el aspecto volumétrico y la presencia de decoración en sus puertas. Las cajas de Chucuito generalmente representan a la Virgen de la Candelaria o Copacabana, la Virgen de la Asunción, y de manera excepcional puede aparecer la cabeza del Ecce Homo (2003, p. 107).

Las cajas de Chucuito del tipo B, presentan una única talla que generalmente es la Virgen de Copacabana, la Candelaria o la Virgen de la Asunción, la imagen se ubica en una hornacina flanqueada por columnas salomónicas y querubines (Mendizábal, 2003, p. 108).

Cuando se abre las portezuelas de las cajas de imaginero de Chucuito se vislumbra un mundo sagrado, la materialización de una hierofanía que se corporiza en los materiales empleados por el artista o imaginero, aunque los materiales sean menos suntuosos que sus similares virreinales. La pasta, el maguey y el estuco, junto con la pintura imitan las obras del pasado; así el imaginero intenta sugerir carnaciones nacaradas y realiza una simulación de los ropajes procesionales en la materialidad del óleo o las anilinas, siendo patente que sigue la convención impuesta por la tradición religiosa para la representación de la Virgen de Copacabana. 
Los retablos portátiles virreinales y las cajas de imaginero del siglo XIX responden a la piedad y la sensibilidad artística imperante durante la época barroca. Formalmente asemeja un tríptico europeo, con imágenes hagiográficas cristianas y en ocasiones pueden contener figuras de animales vinculados al patronazgo de un santo. Estos retablos fueron realizados en diversas épocas, desde el siglo XVII hasta el siglo XX. Existen diversos modelos y variantes a nivel temático, iconográfico y formal. Creadas inicialmente como trampantojos a lo divino, algunos retablos portátiles son veras efigies; recrean la imagen procesional o se basan en pinturas de devociones andinas, donde destaca el culto a la Virgen de Copacabana y al Crucificado ${ }^{1}$.

\section{Creadores, investigadores y las definiciones}

Los retablos portátiles americanos reciben una diversidad de nombres, lo cual genera dificultad en su investigación; se les denomina retablos portátiles, pero también se les conoce por otras denominaciones. Mendizábal (1964) utiliza el término caja de imaginero, en virtud de ser realizado por un imaginero; Ulfe (2011) menciona que se las denomina missas en los Andes peruanos; Sánchez \& Gracia (2013) lo nombran cajón religioso; Bugallo (2010) lo denomina urna, teniendo similitudes con el cajón religioso boliviano, pero las urnas argentinas pueden tener puertas, mientras los cajones bolivianos generalmente carecen de ellas. La definición es fundamental, ya que engloba un sustrato mental y define el objeto artístico, expresando una ideología y dirigiendo la línea de investigación.

San Marcos, sanmarkos y sanmarcos aluden a un mismo objeto artístico, mientras que missa es usado en la puna ayacuchana hasta la actualidad para referirse al sanmarkos. Jiménez (1992) y Ulfe (2011) utilizan la denominación missa, manifestando su uso en la zona rural alto andina peruana; además es la denominación usual para los cajones religiosos de Perú, Bolivia y Argentina. El Museo de Arte de San Marcos (MASM) mantiene la colección de Alicia Bustamante donada por Celia Bustamante en 1970 cuando era director Francisco Stastny. Las fichas técnicas registran la denominación de retablo tradicional para referirse al cajón sanmarkos; mientras que se utiliza el término retablo de la Virgen de la Candelaria al referirse a una caja de imaginero chucuiteña, tipo B.

Arguedas (1958) utiliza los términos retablo y San Marcos de manera equivalente, pero Mendizábal (1964) considera que el termino retablo surge en 1941, y que el sanmarkos no es un retablo, sino una caja de imaginero ayacuchana. Asimismo, afirma que la caja de imaginero sanmarkos se realizaba en el área rural ayacuchana, aunque también en la ciudad de Huamanga, siendo un objeto ritual mágico religioso usado por los ganaderos en la herranza (2003, pp. 105-107). 
Arguedas menciona un pequeño retablo o retablillo de Puno, que representaba a María Santísima en un altar de iglesia andina. El autor comenta que observó el retablillo en la colección de Alicia Bustamante, pero no encontró ninguno similar en Huamanga (esto debió haber ocurrido en la década de 1950). Mendizábal las denomina como cajas de imaginero de Chucuito, sosteniendo la hipótesis de su posible manufactura ayacuchana, aunque fueron encontradas en las iglesias de Pomata y Yunguyo, pertenecientes a Chucuito, región fronteriza con Bolivia (2003, p. 107). Stastny lo denomina pequeño tríptico religioso, también tríptico de Chucuito² (1981, p. 154), aunque la fig. 141, titulada Retablo con Virgen de la Purificación, siglo XIX, sierra sur, es un retablo portátil o caja de imaginero de Chucuito (1981, pp. 48-49).

El estudio de Mendizábal fue publicado en 1963-1964, aunque comenzó a escribirse en 1957; luego reescrito en 1959, cuando el investigador viajó a Huamanga, pudiendo consultar las fuentes primarias y realizar las entrevistas a los imagineros (2003, p. 104). Por su parte, Arguedas realizó las entrevistas antes de 1958, teniendo relación con el movimiento indigenista. Ambos autores vieron los primeros objetos de arte popular y los retablos, Arguedas y Mendizábal tuvieron acceso a retablos, cajas de imaginero y altares portátiles, en Lima, Cuzco y Ayacucho; aunque varias de las obras analizadas son imposibles de localizar, algunas se conservan en museos y colecciones privadas.

\section{Estado de la cuestión}

Subias Galter ${ }^{3}$ (1948) menciona dos objetos similares a los retablos portátiles peruanos, la primera denominada capillita de santero, vinculada a la tradición gótica; la segunda conocida como capillita captiri catalana de posible origen italiano. Estos objetos devocionales representan a la Virgen María, se las supone del siglo XIX o inicios del XX.

Arguedas (1958) realiza una serie de entrevistas a imagineros radicados en Huamanga para establecer los elementos y las escenas del sanmarcos o retablo humanguino, el cual formalmente es semejante a los trípticos europeos; destacando la labor artística de Joaquín López Antay, creador del retablo ayacuchano.

Mendizábal (1963) estudia principalmente el cajón sanmarkos, sus posibles antecedentes formales, la temática e iconografía de las cajas de imaginero ayacuchanas. La investigación es cualitativa, y en una serie de entrevistas recoge el testimonio de los imagineros radicados en Huamanga. El autor emplea un enfoque mixto, utiliza el método marxista, el estudio de las crónicas del siglo XVI-XVII y el análisis formal, incidiendo en los materiales y las técnicas usadas, teniendo en cuenta el contexto histórico y las condiciones tecnológicas de la época. También aplica el método de Meumann para el análisis artístico 
(2003, p. 135), por ello realiza el conteo, codificación de las figuras y una serie de tabulaciones para poder comparar varios sanmarkos del MNCP, siguiendo la línea de estudio de historiadores de arte español como Pijoán (1935) y Subias Galter (1948).

Macera (1979) analiza la pintura popular andina del siglo XIX de los maestros campesinos cusqueños. El autor presenta las devociones más arraigadas en las serranías peruanas. Para ello utiliza el método sociológico y marxista. En el catálogo del libro se encuentran retablos portátiles con puertas pintadas a similitud de la pintura de los maestros campesinos.

Stastny (1981) estudia los sanmarkos, sus escenas pastoriles y sincréticas, mencionando el principio de disyunción para explicar las formas cristianas y los contenidos heterodoxos. $\mathrm{El}$ autor realiza una revisión de los antecedentes formales del arte popular peruano, asimismo de la iconografía de los retablos portátiles y el cajón sanmarkos.

Rivas Plata (1992) realiza un estado de la cuestión de los posibles antecedentes formales del cajón sanmarkos, siguiendo la línea de Mendizábal, los estudios de Stastny y de Macera. El autor recrea las condiciones económicas, sociales y culturales del epígono virreinal, mencionando las investigaciones de Urrutia $^{4}$ sobre el sistema de arriaje y la modificación de las rutas comerciales debido a la caída de la extracción de la mina argentífera de Potosí a partir de 1750, lo cual propició la decadencia de Huamanga e influyó en la distribución del sanmarkos y las cajas de imaginero de Chucuito durante el siglo XIX.

González (2003) menciona objetos similares a la-retablo dedicado a la Virgen se asemeja a las cajas de Chucuito. El autor realiza una investigación histórica y un análisis de las formas de la imaginería y su evolución en el área de la puna argentina de Jujuy y complementa su análisis con dibujos y fotos de la imaginería devocional popular andina.

Muñoz (2003) estudia los retablos portátiles bolivianos y las principales devociones presentes en los retablos o cajas, los cuales reciben distintos nombres según las regiones: Caja de San Marcos, Caja de Imagineros, Tata Cajoncitos, Mama Cajoncitos, Vírgenes, Piedrarayos. Los retablos portátiles en su mayoría son tributarios del barroco mestizo, a pesar de lo impreciso del término. Además, menciona la libertad creativa de los imagineros, ya que son libres de las reglas impuestas por la perspectiva y las formas académicas.

Bugallo (2010) menciona un tipo de urnas de santos con antecedentes en los retablos portátiles virreinales, que ostenta un solo piso, el cual presenta santos patronos de los animales, semejante a los sanmarkos humanguinos. La investigación es cualitativa y etnográfica, basada en entrevistas a profundidad; el estudio se realizó en la puna argentina, en la zona de Jujuy, región limítrofe con Bolivia. Las urnas jujuneñas presentan dos puertas abatibles que pueden estar 
pintadas con motivos florales, geométricos y santos, o estos últimos ser figuras adosadas (p. 90). La autora menciona que la práctica de inclusión de santos patronos de los animales en retablos o urnas es una constante en el área andina latinoamericana, relacionando su investigación con los sanmarkos ayacuchanos; para esto sigue los postulados de Arguedas (p. 98).

Scocchera $(2011)^{5}$, menciona que los retablos portátiles fueron obras devocionales surgidas luego del Concilio de Trento y la Contrarreforma. En su investigación analiza un retablo portátil de la Virgen de Copacabana datado circa 1700, el cual tiene una iconografía similar a los retablos portátiles virreinales peruanos y cajas de imaginero de Chucuito. Scocchera afirma que las flores que aparecen en los nichos son ofrecidas a la Virgen como veneración. El método de análisis es la dialéctica y la teoría de la imagen de Didi-Huberman (pp. 6-7).

Sánchez \& Gracia (2013) consideran que el cajón peruano y el boliviano comparten formas comunes hasta comienzos del siglo XIX, pero será en el novecientos, luego de la independencia del Perú, que se producirá diferencias en el cajón religioso peruano y boliviano; existiendo una continuidad virreinal, pero incorporando variaciones estilísticas, formales y estéticas ligadas a la cosmovisión andina de sus usuarios. La línea de investigación es antropológica y etnográfica, utilizando el análisis histórico-crítico y el método formalista. En los cajones religiosos bolivianos son evidentes la presencia de la cruz, las imágenes de Cristo, la Virgen y Santiago pintadas en piedra.

Oros (2015) en el catálogo razonado para el MUSEF 6 de Bolivia, sigue la línea de Siracusano ${ }^{7}$. Así, la hipótesis que se establece es que los colores y pigmentos (materialidad) usados en la pintura e imaginería virreinal son los mismos insumos antaño usados en la fabricación de illas y huacas. La autora considera la posibilidad de que la policromía de tonos fuertes e intensos de los retablos o cajones, evoque los pigmentos de las huacas. Para Oros la apariencia de retablos y piedra santos es católica, pero la materialidad está asociada a las huacas, illas o corporiza a entidades como Illapa y la Pachamama.

Labán $(2016)^{8}$ realiza un estudio sobre los diversos objetos artísticos denominados genéricamente como retablos. Así, realiza un análisis basado en el método formalista y el análisis histórico-crítico para clasificar los retablos virreinales, nichos, capillitas y cajas de imaginero o missas. Siguiendo los estudios de Mendizábal y Stastny, realiza un análisis de las cajas de imaginero de Chucuito, destacando sus antecedentes virreinales, así como la composición de simetría axial y los diseños florales que comparten con el cajón sanmarkos. Además, compara las cajas de imaginero peruanas con sus similares argentinas y bolivianas, indicando la problemática en torno a la necesidad de clasificación de los retablos portátiles americanos. 


\section{Antecedentes históricos}

Los altares portátiles y trípticos llegaron con los evangelizadores, junto con los catecismos y el pensamiento religioso anclado en la piedad medieval. La imagen fue vital en el proceso de conversión y evangelización de los naturales. Los trípticos o retablos portátiles se difundieron en el Virreinato peruano, junto con la iconografía devocional de la contrarreforma católica.

Los altares portátiles sirven para oficiar la liturgia, por lo cual deben ser consagrados, y solo son de uso del sacerdote, mientras los trípticos o retablos portátiles de pequeñas dimensiones eran para la devoción personal, la piedad doméstica o conventual, pero también fueron símbolos de poder.

Esteras (1997) denomina capilla-retablo, a los retablillos de caja de plata y pasta de estuco mezclada con maguey. La autora asevera que los antecedentes son hispánicos, pero el prototipo con seguridad es altoperuano, aunque se pudo fabricar en otras regiones. Fueron realizados en los siglos XVII-XVIII, generalmente eran de pequeñas dimensiones y asemejaban trípticos que representan a la Virgen de Copacabana en su altar. Su manufactura fue primorosa, realizados con suntuosos materiales, siendo obras piadosas y de gran hermosura que se conservan en colecciones privadas, museos y conventos españoles (p. 114). Estos son los antecedentes de las cajas de imaginero de Chucuito tipo A.

Las demandas y retablos portátiles fueron prohibidos en 1831 por la $\mathrm{Mu}-$ nicipalidad de Lima por ser un culto que escapaba del control central de la Iglesia y llevaba al exceso. En la evangelización lo portaban los sacerdotes y los doctrineros, a fines del siglo XVIII lo llevaban los demanderos. (Majluf \& Wuffarden, 2004, p. 264).

Mendizábal es el primero en considerar la vinculación entre la pintura de los maestros campesinos cusqueños ${ }^{9}$ y los cajones sanmarkos; esto al percatarse de la similitud de las representaciones. Considerando que los cajones sanmarkos son la elaboración posterior y de mayor complejidad de las pinturas de los maestros campesinos cusqueños (2003, pp. 130-131). Stastny (1981) menciona dos tipos de sanmarkos, el primero es un relieve en piedra de Huamanga, tallada y policromada, y el segundo, el cajón sanmarkos. Ambos con la iconografía de los santos patrones, las escenas pastoriles y agropecuarias. La iconografía se habría gestado en el epígono virreinal, en los talleres de los primitivos cusqueños o pintores campesinos del siglo XIX; luego migra a los talleres ayacuchanos (pp. 154-156). En cambio, la hipótesis de Macera (1982) es que el sanmarkos comenzó a producirse a fines del siglo XVII e inicios del siglo XVIII, además afirma que del sanmarkos migraron las escenas agropecuarias a la pintura de los maestros campesinos cusqueños del siglo XIX. 


\section{Métodos y dificultades en el estudio de los retablos}

Del acervo de obras, varias están sin documentar, no existiendo registros, ni fichas técnicas. Las obras que están catalogadas y con fichas técnicas en los museos, utilizan diversas denominaciones; lo cual complica su estudio. La mayoría de las obras son anónimas y se ignora la procedencia, su pertenencia a un taller y la datación cronológica. Los textos también ofrecen discrepancias, así una obra puede ser datada en el siglo XIX o en el XX, ser cusqueña, altoperuana o ayacuchana; por ejemplo, el retablo de la Virgen de Copacabana del MALI es para Mendizábal (1964) de origen ayacuchano, para Esteras (1997) del Alto Perú, y el MALI lo considera de procedencia cusqueña $a^{10} \mathrm{o}$ altoperuana.

Existe la obra, pero sin contexto que ayude a su comprensión y análisis; por ello el análisis formalista es de vital importancia en una historia del arte sin nombres, donde el artista es un imaginero anónimo, heredero de formas y maneras de hacer de antaño, lo cual puede llevar a una datación incorrecta, ya que el imaginero maneja un repertorio iconográfico y técnicas desfasadas a la época histórica en la que está inserto. Esta paradoja es mencionada por Focillon (2005), al comentar la historia de las formas:

De hecho, los periodos de la historia de las formas no son homogéneas y admiten simultáneamente tentativas, cumbres y decadencias. Los siglos se suceden los unos a los otros sin que cada uno de ellos tenga su tonalidad perfectamente unificada. Todas las regiones, en un momento determinado, no viven en la misma época. El arte del periodo románico, no es necesariamente románico. El arte románico se sobrevive o mejor dicho sobrevive a su actualidad en pleno periodo gótico. (p. 29)

Esta reflexión se refiere a la escultura románica, pero es válida para el arte popular del siglo XIX. Las formas pueden mantenerse, llegar a su apogeo y desaparecer; en algunos lugares alejados o aislados, formas arcaizantes y costumbres del pasado pueden estar en plena vitalidad; así, en regiones inhóspitas, aunque pasen los siglos y los estilos muden, sus formas pueden ser autónomas, respecto a las convenciones formales imperantes en las capitales.

$¿$ Puede una obra de arte no reflejar el sentir de una época o los valores generales de una época? La obra de arte puede responder a una región determinada, a las formas de la imaginería devocional de sus creadores que es tributaria de una piedad pretérita, a los sistemas de creencias validos en una región específica, siendo un arte de la periferia. Sus formas remitirán a la época relativa ${ }^{11}$ del lugar, como ocurre en las zonas rurales. La escultura románica presenta tendencia al antinaturalismo, la esquematización y la frontalidad; además Focillon (2005) enuncia dos leyes generales: la ley del marco y del esquema geométrico. En el arte popular peruano del siglo XIX se puede aplicar las leyes generales de Focillon y se evidencia la tendencia a la esquematización 
Lo relativo de la época histórica y los estilos, también es mencionado por Focillon (1947); así señala que "muchos estilos pueden vivir simultáneamente, aun en regiones muy próximas, hasta en una misma región" (p. 22). Los estilos pueden ser diversos en las regiones; varios estilos pueden convivir en una región. En Cusco las formas de la pintura cusqueña del siglo XVII-XVIII serán retomadas a inicios del siglo XIX por los "primitivos cusqueños" y de ahí migran al sanmarkos en alabastro y luego a las cajas de imaginero sanmarkos. La imaginería de tendencia virreinal sobrevivió en las provincias durante todo el siglo XIX.

El estilo es un elemento básico, para ello seguimos los postulados de Wölfflin (1915), considerando los tres componentes del estilo: individual (estilo del artista), nacional o estilo de representación tradicional (formas convencionales de representación de una región) y de época.

Sobre el arcaísmo en el arte americano, Labán (2016, p. 60) sigue la línea de Stastny (1994) que manifiesta el uso de las estampas y formas arcaizantes en la evangelización y adoctrinamiento indígena; las formas artísticas del siglo XVII estaban basadas en la piedad medieval: los Evangelios Apócrifos y la Leyenda Dorada. El barroco americano es diferente al europeo, debido a sus elementos ideológicos y plásticos sacados del mundo medieval, además de tener formas barrocas y manieristas. La planimetría, la tendencia a lo lineal y no a lo pictórico (Stastny, 1994, pp. 22-25), son elementos presentes en el arte barroco americano; pero también en el arte popular de fines del siglo XIX, con reminiscencias del barroco andino peruano. Por lo tanto, los conceptos fundamentales enunciados por Wölfflin, son de gran valor para el análisis formal de la obra; asimismo, lo referido a lo clásico y lo barroco.

Las cajas de imaginero son planimétricas - aunque algunas presentan profundidad-; generalmente evidencian tendencia a lo lineal, con formas cerradas, y bordes precisos, siendo según los postulados de Wölfflin más cercanas a los conceptos referido a lo clásico que a lo barroco.

Stastny $(1981,1998)$ menciona las dificultades metodológicas para la aplicación del método iconológico e iconográfico en el barroco americano y el arte popular, debido a la esteriotipación de los personajes, los mecanismos de aculturación y la resignificación simbólica. Labán (2016) considera, por lo expuesto, que el análisis del contenido natural (preiconográfico) es válido y fundamental en el estudio del arte popular tradicional peruano (p. 36). Las objeciones al método iconológico e iconográfico por parte de Stastny son lucidas, basadas en la particularidad del arte popular peruano. Por ejemplo, en los cajones sanmarkos, el evangelista San Marcos es patrón del toro, aunque la iconografía indica que su animal acompañante es el león. Domínguez (1987) realiza un estudio sobre una antiquísima festividad, donde la leyenda hispánica hace a San Marcos pa- 
trón del toro, celebrándose en Extremadura desde el siglo XVI, la fiesta del toro de San Marcos (pp. 49-53).

Asimismo, cuando Mendizábal y Arguedas realizan las entrevistas a los imagineros ayacuchanos a mediados del siglo XX, para saber sobre la conformación de un sanmarkos, los imagineros indicaban versiones similares, pero también notables diferencias; así un santo cambiaba de iconografía, función o de patronazgo.

\section{Conclusiones}

- Las rutas de la plata y los santuarios fueron vitales en la difusión de los retablos portátiles, delimitando su zona de difusión y el circuito de distribución de los retablos y cajas de imaginero en Latinoamérica.

- Los retablos portátiles y cajas de imaginero presentan en su mayoría el estilo barroco andino, teniendo tendencia a la planimetría, la profusión decorativa y las técnicas de la imaginería virreinal, destacando el empleo de materiales como el estuco policromado, el maguey y la plata.

- La evangelización dio los temas que se representó en el arte popular peruano del siglo XIX, el barroco junto con la iconografía religiosa permaneció, aunque con modificaciones simbólicas y variaciones a nivel del significado.

- El análisis formalista es de vital importancia para establecer un estudio de obras sin contexto, consideradas de autores anónimos, y sin datación cronológica exacta.

- Las cajas de imaginero de Chucuito y los cajones sanmarkos son modelos paradigmáticos de retablos portátiles peruanos del siglo XIX, con antecedentes virreinales e insertos en el sistema mítico y religioso andino.

- La iconografía puede ser empleada en el arte popular, pero esto no implica que se mantenga los significados, es posible un corpus de significaciones dinámicas en torno a un determinado personaje o atributo; así, la iconografía debe ser empleada con reserva, por la presencia de la disyunción.

\section{Notas}

1 Existen dos retablos portátiles del Señor Crucificado del siglo XIX; ambos se encuentran en la colección de Mari Solari y uno es de origen cusqueño.

2 En la nota 159, p. 154 el autor indica que se encontraban en Chucuito.

3 Historiador y crítico de arte catalán, su nombre fue Joan Subias i Galter; realizo investigaciones en catalán y español; conocido en lengua hispana como Juan Subias Galter. Recuperado el 25 de agosto de 2015 en http://www.enciclopedia.cat/EC-GEC-0064364.xm

4 Jaime Urrutia es un investigador e historiador ayacuchano, autor de Comerciantes, arrieros y viajeros $1770-1870$. 
5 Revisamos la versión digital, fue publicado en Avances, Revista de artes, Nro. 19, 2011-2012, de la Universidad Nacional de Córdoba, Facultad de Filosofía y Humanidades, CEPIA, Córdoba, Argentina, pp. 191-209, vol 1, 2011.

6 Museo Nacional de Etnografía y folklore.

7 Siracusano desarrolla esta tesis en El Poder De Los Colores: De Lo Material a Lo Simbólico En Las Prácticas Culturales Andinas. Siglos XVI-XVIII.

8 En Tradición y recreación en el retablo ayacuchano de la familia Jiménez (1980-2000), en el capítulo I: Los "retablos": altares portátiles, cajas de imaginero (missas) y el retablo ayacuchano. Realiza un estudio para clasificar los retablos con la finalidad de estudiar el retablo ayacuchano.

9 Mendizábal indica que las pinturas fueron encontradas hace unos años, siendo el artículo de 1963-1964. Debieron encontrarse alrededor de la década de 1950. Estaban en la zona sur cusqueña; de influencia colla, las pinturas tienen las escenas del mundo campesino, los santos usuales del sanmarkos, además de San Isidro Labrador y Santiago apóstol. La descripción coincide con la pintura de los maestros campesinos cusqueños del siglo XIX, también denominados primitivos cusqueños. Aunque Mendizábal estima que son de mediados o fines del siglo XVIII. (2003, pp.130-131)

10 En Catalogo de la exposición Plata de los Andes (2018) se indica que la obra es cusqueña o del Alto Perú, pero en el Archivo Digital de Arte Peruano (ARCHI) se consigna como anónimo cusqueño, http://www.archi.pe/index.php/foto/index/4872, igual en la colección virtual del MALI, http://190.12.86.155/coleccionvirtual/view/objects/asitem/People@769/0?t:state:flow=b0a8797b-4988-41f2-9f65-b20ac9563e3b

11 Con este término nos referimos a que en regiones alejadas se puede mantener un sistema artístico, cultural y económico que no corresponde a su época histórica sino a una época anterior. Existen sociedades que mantienen sus tradiciones y costumbres ancestrales y parecen vivir en un tiempo remoto.

\section{Referencias bibliográficas}

ARCHI. Archivo Digital de Arte Peruano. (2019). Retablo portátil Virgen de Copacabana. Recuperado de: http://archi.pe/index.php/foto/index/4872

Arguedas, J. (1958). Notas elementales sobre el arte popular religioso y la cultura mestiza de Huamanga. Revista del Museo Nacional, XXVII, pp. 140-194.

Arguedas, J. (2011). Formación de una cultura nacional indoamericana. México: Siglo XXI editores.

Bugallo, L. (2010). La estética de la crianza. Los santos protectores del ganado en la Puna de Jujuy. En Alba Bovisio, M. y Penhos, M. (cords.). Arte indígena: categorias, prácticas, objetos (pp.85-102). Catamarca: Editorial Brujas.

Domínguez, J. (1987). La fiesta del "toro de San Marcos" en el oeste peninsular. En Revista de Folklore. Tomo 7b. Núm. 80, pp. 49-58. Recuperado de http://www. cervantesvirtual.com/obra/la-fiesta-del-toro-de-san-marcos-en-el-oeste-peninsular-ii/

Esteras, C. (1997) Platería del Perú Virreynal. 1535-1825. Lima: Banco Continental.

Focillon, H. (1947). Vida de las Formas. Buenos Aires: Librería y editorial El Ateneo. 
- (2005) La escultura románica. Investigaciones sobre la historia de las formas. Madrid: Ediciones Akal.

González, R. (2003). Imágenes de dos mundos: la imaginaria cristiana en la puna de Jujuy. Argentina: Fundación Espigas.

Gran Enciclopèdia Catalana. (2005) Joan Subias i Galter. Recuperado el 25 de agosto de 2015 de: http://www.enciclopedia.cat/EC-GEC-0064364.xm.

Huertas, E. (1987). Vida y obras de Florentino Jiménez Toma. Ayacucho: Centro de Desarrollo Agropecuario.

Jiménez, E. (1992). Santeros, "missas" y herranza en el campo ayacuchano. En El retablo ayacuchano. Un arte de los Andes (pp. 27-35). Lima: Instituto de Estudios Peruanos.

Labán, M. (2016). Tradición y recreación en el retablo ayacucbano de la familia Jiménez (1980-2000). (Tesis para optar por el grado de Magister en Arte Peruano y Latinoamericano) Universidad Nacional Mayor de San Marcos, Lima. Recuperado de: http://cybertesis.unmsm.edu.pe/handle/cybertesis/5047

Macera, P. (1979). Pintores Populares Andinos. Lima: Banco de Los Andes.

- (1982). Los retablos andinos y don Joaquín López Antay. Boletín de Lima, 19, pp. 15-35.

Majluf, N. y Wuffarden, L. (2004). Arte en piedra de Huamanga. En E. Rivera (ed.) Antologia de Huamanga (pp. 261-266). Lima: Fundación Manuel J. Bustamante de la Fuente.

Museo de Arte de Lima. (2019). Anónimo cuzqueño. Retablo portátil de la Virgen de Copacabana. Recuperado de: http://190.12.86.155/coleccionvirtual/view/objects/asitem/People@769/0?t:state:flow=b0a8797b-4988-41f2-9f65-b20ac9563e3b

Mendizábal, E. (1963-1964). La difusión, aculturación y reinterpretación a través de las cajas de imaginero ayacuchanas, Folklore Americano, pp. 11-12, 115-333.

Mendizábal, E. (2003). Del sanmarkos al retablo Ayacucho: dos ensayos pioneros sobre arte tradicional peruano. Lima: Fondo Editorial de la Universidad Ricardo Palma, Instituto Cultural Peruano Norteamericano.

Muñoz, M. (2003). Del Barroco Mestizo al arte popular actual: Los retablos portátiles. En Barroco andino: Memoria del I Encuentro Internacional sobre Barroco. La Paz: Viceministerio de Cultura, pp. 221-228.

Oros, V. (2015). Retablos y piedras santos La materialidad de las wak'as. La Paz: Museo Nacional de Etnografía y Folklore-MUSEF. Recuperado de: http://www.musef.org.bo/catalogos/2015_Retablos_y_piedras_santos.pdf

Panofsky, E. (2005). Estudios sobre iconología. Madrid: Alianza editorial.

Pijoán, J. (1935). Arte cristiano primitivo. Arte Bizantino. En Summa Artis. Madrid: Espasa-Calpe. 
Rivas Plata, I. (1992). Antecedentes europeos y españoles del retablo. De la capilla de santero al cajón sanmarcos". En Retablo ayacuchano: un arte de los Andes, (pp. 5-16). Lima: Instituto de Estudios Peruanos.

Sánchez, L. \& Gracia, O. (2013). Cajones arte popular y memoria religiosa. Cochabamba: Instituto de Investigaciones Antropológicas y Museo Arqueológico, UMSS. Recuperado de: http://www.museo.umss.edu.bo/wp-content/ uploads/2013/09/catalogo-cajoneslow.pdf

Sánchez, W. (2015). El cajón ritual-religioso campesino: entre lo global y lo local. En Garcés, F. \& Sánchez, W. (ed.). Textualidades: entre cajones, textiles, cueros, papeles y barro, pp. 7-38. Cochabamba: Universidad Mayor de San SimónInstituto de Investigaciones Antropológicas y Museo Arqueológico.

Scocchera, V. (2011). La preservación de la imagen sagrada en nichos y retablos portátiles coloniales del virreinato del río de la plata (fines del siglo XVII - fines del siglo XVIII) en Avances, 1(19) ,191-209. Recuperado de: https://www. academia.edu/5062581/LA_PRESERVACION_DE_LA_IMAGEN_SAGRADA_EN_NICHOS_Y_RETABLOS_PORTATILES_COLONIALES_DEL_ VIRREINATO_DEL_RIO_DE_LA_PLATA_FINES_DEL_SIGLO_XVII_ FINES_DEL_SIGLO_XVIII

Stastny, F. (1981). Las artes populares del Perú. Madrid: Edubanco.

—. (1994). Sintomas medievales del "Barroco americano". Lima: Instituto de Estudios Peruanos.

Subias Galter, J. (1948). El arte popular en España. Barcelona: Seix Barral.

Ulfe, M. (2011). Cajones de la memoria: La bistoria reciente del Perú a través de los retablos andinos, Lima: Fondo Editorial Pontificia Universidad Católica del Perú.

Wuffarden, L. \& Kusunoki, R. (Eds). (2018). Plata de los Andes. Lima: Asociación Museo de Arte de Lima. 